recently introduced materials are discussed. An outstanding feature of the book is the concise, clear manner in which practical recommendations are given.

The necessity for such an authoritative series of volumes of reference can be understood when it is remembered that, until recently, building practice was subject only to very gradual changes. The rapid developments of modern times have led to the introduction of a multitude of innorations, some of which can be described as ill-advised. In showing the designs and methods which have been closely scrutinized, and finally approved at the Building Research Station, this volume can be seen to be an invaluable contribution to the formulation of a code of good practice. It has been attractively prepared, is profusely illus. trated with photographs, drawings and graphs, and is supplemented by lists of references and of appropriate British Standard Specifications.

\title{
THE CALIFORNIAN DESERTS
}

\section{(I) The Californian Deserts :}

a Visitor's Handbook. By Edmund C. Jaeger; with Chapters by S. Stillman Berry and Malcolm J. Rogers. Revised edition. Pp. x+209. (Stanford University, Calif. : Stanford University Press ; London : Oxford University Press, 1938.) 9s. net.

(2) Deserts

By Dr. Gayle Pickwell. (Whittlesey House Publication.) Pp. xiv +174 (64 plates). (New York and London: McGraw-Hill Book Co., Inc., 1939.) $15 s$.

(1) TERE is a model guide-book, for its presentation is artistic, its facts correct and well chosen and the deductions therefrom modern. A desert is a place of high summer temperatures with steady, drying winds and a rainfall not exceeding five inches; these are usually accompanied by a high, diurnal temperature range, here about $40^{\circ} \mathrm{F}$. There are complications, for the raincarrying winds rise in the Gulf of California, cross mountains and descend in occasional bursts on a dissected, mountainous land, extending from the Colorado River for two hundred miles along the inland half of California. The possible evaporation appears to be $80-100$ inches, so that the intensity of the aridity is considerable. These conditions have only been reached since the end of the Pleistocene, and there would appear to have been several periods of wetness. To the south the fertile belt of the Colorado separates the similar desert of Arizona and Sonora (Mlexico), and there have always been in both deserts lake and other areas of permanent water such as the famous 'Death's Head Valley' and the 'Salton Sea' in California.

Comparisons with Old World deserts are impossible, for here are more than seven hundred species of plants. Many are supposedly desertadapted, but caution is advised, since marsh and bog plants, owing to an absence of nitrogen, may show similar changes. Some of the peculiar races are doubtless evolutions of northern plants, but there has probably been extensive immigration from the high, more ancient desert-lands of Sonora.

Insects are a function of plant-growth, so that there must be several thousand species, mostly living in inconspicuous habitats; the most visible are treated of in an interesting chapter. Snails and higher animals are well considered, the whole leading to a naturalist's account of the mammals, which are represented by thirty-six genera, including beavers which have given up the dam-making habit. The preservation of the bighorn sheep, of which about 600 are left, is immediately important, since experience has shown that the area occupied by a wild race of sheep which has been destroyed cannot be readily repeopled by sheep from other areas.

The Californian deserts are laboratories, conveniently situated for study; the experimental research is that of Nature, the lines those of past times, and hence peculiarly suited to the study of the changes which are due to natural evolution.

(2) Dr. Pickwell in his turn provides 64 full. plate photographic illustrations of these same deserts. His text for the most part is explanatory of these, to which is often added original observa. tions on the biology of some of the plants and animals pictured. Unfortunately, many of the reproductions appear rather black-and-white so that frequently where detail is needed in the plants, it cannot be found. $\mathrm{My}$ own experience in similar landscape photography in the tropies leads me to suggest that for plants and forests a side light with consequent low-toned shadows is desirable, my practice being to close the camera for the six hours of midday. A concluding chapter summarizes the desert features and problems, subjects upon which experimental researches are urgently required, especially in respect to the water requirements of animals.

J. S. Gardiner. 